\title{
An Integrated Application-oriented Teaching Reform Method of Network and Information Security
}

\author{
Y. Wang \& H. LI \\ College of Computer Science, Inner Mongolia University, Hohhot 010021, China
}

\begin{abstract}
On the basis of experience and taste in experimental teaching of network and information security, this paper analyzes four elements of the experimental teaching, and constructively put forward three directions of the experimental teaching reform, including experimental design for ability training, new roles and relationships between teacher and student and experimental model with actual experiment and simulation experiment. Then the paper discusses the reform objective, reform methods and specific contents of each direction in details.
\end{abstract}

KEYWORD: Network and information security; Experimental teaching; Teaching method

\section{INTRODUCTION}

In recent years, with the increase of social demand for applied talents, the focus of science teaching has transferred from theory to practice in many universities. These universities scale up efforts to the practical teaching in the course and highlight cultivating the students' quality of practice and innovating abilities. Network and information security is a core course with extensive application in computer network, and its main teaching contents include host security, network security and cryptography, etc. As a kind of engineering course, it should not only make the students master relevant theoretical knowledge through classroom teaching, but also train the students' ability of network security detection, processing and defense based on the actual application requirements. Therefore, in the setting and implementation of the course, it is very necessary to strengthen the practice teaching link and design reasonable experimental contents.

At present, many colleges and universities have a series of reforms and explorations from the two aspects of hardware and software according to their characteristics of talent cultivation. In the aspect of hardware, they strengthened construction of the laboratory and enriched the experimental resources, which made the experimental environment as far as possible to meet the requirements of the high level experiments. In the aspect of software, they reformed the practice teaching methods, which encouraged the student's study enthusiasm and promoted the raising of experiments teaching level. However, due to the development of science technology, the change of social demand and the differences of the students, how to make the experimental structure of network and information security applicable to new requirements is still worth exploring.

\section{THE REFORMING DIRECTIONS OF EXPERIMENTAL TEACHING}

The experimental teaching of network and information security is composed of four elements, including teacher, student, experimental content and experimental tool or environment. The four elements are not isolated, but interrelated and interacted.

The teacher designs the content of experimental teaching according to the requirements of the teaching content, and the experimental content depends on the existing experimental tools and environment. The student completes the experimental task assigned by the teacher by using the corresponding experimental tools or equipments. At the same time, the teachers are also responsible for guidance, supervision and inspection to the students' works in experimental implementation.

In the process of experimental teaching, whether the relationship between the four elements can be handled or not is a key problem to achieve good results of experimental teaching. It includes two aspects: one is how to effectively coordinate the relationship between teacher and student and the relationship between experimental content and experimental tools or environment so as to promote 
the teacher to set up a more reasonable experimental content and arouse the student's enthusiasms; the other is how to strengthen the support from experimental tools or environment for experimental content under current conditions.

In order to make the experimental teaching of network and information security more effective, this paper explored the reform of experimental teaching from the experimental content, experimental tools and the roles of teacher and student in the teaching process. In the process of the reform, we fully embody the experimental teaching for basic knowledge, basic technology and basic skills training as traditional teaching. In addition, we focused on the integrated application of three methods, which include experimental design for ability training, new roles and relationship between teacher and student and experimental model with actual experiment and simulation experiment.

\section{THE CONTENT AND METHOD OF TEACHING REFORM}

\subsection{Experimental design for ability training}

The cultivation of innovative ability is an important goal of experimental teaching. In order to adapt to different levels of training goal, many colleges and universities classify experiments into validating experiment, operational experiment, comprehensive experiment and design experiment according to the experimental content [1].

However, this compartmentalization can't reflect well on various needs for the cultivation of the student's ability. The student's innovation ability is the integrated embodiment of many specific abilities, including problem-finding character, problemsolving character [2], imagination, experimental design, technology development, product improvement and application, etc. So it is necessary to build a more granular ability-oriented experimental system. Combining with the requirements and goals of network and information security curriculum of our school, we will hope to discuss a better teaching method to cultivate the student's ability from knowledge-learning ability, problem-finding and problem-solving ability, experiment-designing ability and learning transfer ability.

The teaching goal of the experiments based on knowledge learning ability is to for students to learn basic knowledge and principle of network and information security and reinforce the content of the classroom teaching, such as cryptography and application experiments. The teaching goal of the experiments based on problem-finding and problemsolving ability is to for students to learn how to find the problems in the actual network environment, and then find their knowledge to solve these problems so as to gain deep understanding of network security. This type of experiments is helpful to cultivate the student's ability to apply theory to practice, including scripting attacks, vulnerability scanning and network sniffer, etc. The teaching goal of the experiments based on experiment-designing ability is to for students be familiar with both offensive and defensive strategy and further deepen their understanding of network security and information security, such as interactive network attacking and defence. The teaching goal of the experiments based on learning transfer ability is to for students use a kind of theoretical knowledge or principle which has been learned to resolve some similar problems through self-study [3]. This type of experiments is one of the boldest attempts in the teaching reform, including viruses and trojans design, etc.

\subsection{Building a new roles and relationships between teacher and student}

Teacher and student are the two main roles in teaching activity, which constitute the basic relationship of teaching and learning. Traditional experiment of network and information security takes the teacher as the center in teaching process, following a basic process of "imparting knowledgedesigning experiments based on the knowledgearranging experiments-checking the experimental results". In this process, the student can only passively accept, and step by step to complete the experimental task, which is bound to play the participating role and prevents him from using his creative potential. The constructivism's learning theory emphasizes taking the students as the center, which asks the student to transfer his role from passive recipient of external stimulation to active information processor and builder, while asks the teachers to be transformed to the student's helper and promoter [2]. This kind of teaching method drastically promotes the student's active learning, but ignores the teacher's leading role, which can lead the student to deviate from his teaching goal.

Therefore, some education workers put forward a teaching model of complementary advantages, namely the teacher playing a leading role and the student play subjective role [4].In our reform, the idea was used to handle the relationship between teacher and student in the experimental teaching.

The function of the teacher's leading role is the following three steps: experimental design, experimental monitoring and experimental evaluation. The leading role requires the teacher to fully grasp the teaching goal and content and carefully design the experiments based on various capability cultivation. Meanwhile the teacher should act as the role of helper and promoter to guide the student to independently complete experimental 
process as much as possible in the process of experimental implementation. In the experimental evaluation stage, the teacher should give the student more space to think about some open questions. For student, he should give full play to his initiative in the experimental process, carefully analyze the situations and think the problems, and then identify and solve the problems on his own.

\subsection{Experimental model with actual experiment and simulation experiment}

At present, our school has introduced a set of teaching experimental system of network and information security to support the experimental teaching. Simulation experiments in the system are an extension of the traditional experimental teaching, which is convenient for observation, design and participation in the actual operation [5]. This kind of experiments greatly broadens experimental projects and expands the student's horizon. More importantly, the students can complete their learning process and determine their individual needs according to their own rhythm.

But because of the complexity, the diversity and dynamics of the experiment contents of network and information security, the fixed experiments in existing lab system will not be fully meet educational requirements of the course. In addition, the experiments of simulated attack in a fixed environment lead to the students' lack of comprehensive analysis and processing ability in the actual environment [6]. So the experimental setup of network and information security should be the combination of actual experiment and simulation experiment so as to create an integrated experimental platform for students.

The verified experiments or learning experiments should mainly be based on simulation experiments, and then the students can master and understand the process and principle of network attacking and defence through the teaching experimental system. The experiments for threat detection and security defence should mainly be based on actual experiments, and then the students can grasp the teaching contents of network and information security at a higher level through capturing and analyzing packets in the real network. Besides that, we should pay attention to the connection and cohesion between the experiment contents, and make the previous experiments be a basis of the next experiment as much as possible to avoid repeated experiments on the same knowledge.

\section{CONCLUSION}

Through several years of reform explorations and constructions, the teaching team of computer network in our school has become a regional excellent teaching team. Network and information security is a core course in computer network, so it is the teacher's responsibility to deepen the reform of its experimental teaching according to the training objectives and characteristics. The contents described in this paper come mostly from the personal teaching experience, and some theories and assumptions need to be further perfect and improved in practice. In order to achieve better teaching effect, we will explore the teaching method with more diverse forms in future teaching.

\section{REFERENCES}

[1] Li P., The practice teaching reform of computer network series curriculum. Computer education, 17, pp. 61-64, 2010.

[2] He K.K.," Leading -" The theoretical basis of "Leading Subject" teaching structure. Education technology communication, 9(3), 2001.

[3] Rebello N S, Cui L, Bennett A G, et al, Transfer of learning in problem solving in the context of mathematics and physics. Learning to solve complex scientific problems, pp. 223-246, 2007.

[4] Wasley P A. Teachers who lead: The rhetoric of reform and the realities of practice. New York: Teachers College Press, 1991.

[5] Liu L., Chen K., Zhou X., Reform and practice of computer network experiment teaching. Experimental Technology and Management, 12:036, 2007.

[6] Chen T, Hu W, Shi Q. Teaching reform of information security curriculum of distance learning. Proc. Of First International Workshop on Education Technology and Computer Science, IEEE: pp. 185-189, 2009. 